\title{
Examination between the measured and estimated parameters of the participants in the Hungarian Defence Forces Body Composition Program
}

\author{
Attila Novák ${ }^{1,5 *}$, Bea Hornyák ${ }^{1,2}$, Zsófia Rázsó', Szabolcs Szalánczi', Andrea Sótér1,2, Csaba Nyakas ${ }^{3,4}$ \\ ${ }^{1}$ Department of Health Promotion, Hungarian Defence Forces Medical Center, Budapest, Hungary, ${ }^{2}$ School of Doctoral Studies, National \\ University of Public Service, Budapest, Hungary, ${ }^{3}$ Department of Faculty of Health Sciences, Semmelweis University, Budapest, Hungary, \\ ${ }^{4}$ Department of Morpholpgy and Physiology, University of Physical Education, Budapest, Hungary ${ }^{5}$ Doctoral School of Health Sciences \\ Semmelweis University, Budapest, Hungary
}

\begin{abstract}
Introduction: The aim of the research was to analyze the - Introduced in 2015 as a new force protection capability - Hungarian Defence Forces Body Composition Program (HDF BCP) participants' pattern of the measurement parameters and their relationship to each other, furthermore, to create a measurement protocol that can be used with large number of elements, which allows the estimation of strength and fat-free mass in the following.

Methods: The examination was carried out between 2017 and 2020. Within the HDF BCP, the measured and estimated parameters of 283 volunteers between the ages of 18 and 67 years old. A total of 709 measures were made. A Premium Body Impedance Analyzer 500 (BIA) instrument was used for the examinations. In addition, a DYNA 16 strength meter (DYNA) was used which makes it possible to measure the grip strength of both hands at the same time. Statistical calculations are performed with R-Studio program.

Results: An increase in the phase angle is accompanied by an increase in the maximum hand grip strength $(p<0.001)$. The full body strength increases with weight gain regarding both sexes in all age groups tested $(p<0.001)$. Our linear regression model is suitable for estimating maximum hand grip strength using body weight, fat-free mass, age, and gender values $(R 2=0,74)$ and to estimate fat-free mass percentage based on body weight, maximum hand grip strength, and gender values $(\mathrm{R} 2=0,78)$.

Conclusion: The use of phase angle is an important indicator of a lifestyle change program. In the created linear regression model we will be able to estimate body fraction in significant numbers with high accuracy after measuring minimum parameters.
\end{abstract}

Keywords: Physical appearance; physical strength; lifestyle change program; phase angle; hand grip strength; military health

\section{INTRODUCTION}

The Hungarian Defence Forces (HDF) considers it important and gives priority to the physical and mental condition of soldiers. It is essential for their preservation and changes in a positive way to put a special emphasis on the development and maintenance of a healthy lifestyle. To achieve this, the Hungarian Defence Forces Body Composition Program (HDF BCP) was established in 2015, which is provided by the prevention staff of the HDF Medical Centre in the framework of the occupational health promotion. Introduced in 2015 as a new force protection capability, the spirituality of the HDF BCP and its contents

*Corresponding author: Attila Novák, Barackos út 88. Szentendre 2000, Hungary. E-mail: novakattila09@gmail.com

Submitted: 10 November 2021/Accepted: 16 February 2022

DOI: https://doi.org/10.17532/jhsci.2022.1597 stands in accordance with the principles of the health force protection defined in NATO doctrines, with the prevention policy and health preservation objectives of the HDF. Those who serve in the HDF with a high body weight and/ or body fat percentage are inspected by professionals who provide an individualized exercise program after health assessment, dietary counseling based on menu analysis depending on the needs, sample dieting, and psychological support, which can greatly contribute to the building of the right physique. The legal basis of the HDF BCP is established by Decree 10/2015 (July 30, 2015) of the Ministry of Defence on Health, Psychological, and Physical Fitness for Military Service and the Review Procedure, pursuant to paragraphs $16 . \$(3)$ and $12 . \$(2)$, if the soldier does not possess the physique indicators specified in Decree, Annex 3, points $(\mathrm{N}),(\mathrm{O})$, and $(\mathrm{P})$, it should be made aware of the possibility to participate (1). Obtainable data from regular and routine surveys of patients' body 
composition provide useful information for health-care professionals working in the field of clinical practice as the amount and proportion of lean body mass and fat mass come up as prognostic factors for disease outcome (2-4). Several publications have appeared in connection with the fact that abnormal body composition has an adverse effect on morbidity, mortality, regeneration, increases the length and costs of hospital stays, and impairs quality of life (2-5). International recommendations have already defined the means and methods of body composition analysis, the normal limits as well as the treatment procedures used in pathological cases (3-6). It is a prognostic indicator of many chronic diseases and described as a prognostic device in several clinical situations, such as HIV, liver cirrhosis, chronic obstructive pulmonary disease, lung cancer, and dialysis patients $(7,8)$. The phase angle varies with age and gender, and according to some ideas, it can even be a global marker of health. In the HDF BCP, we consider the value of the phase angle as an important indicator in terms of the lifestyle changes proposed - eating restrictions, physical activity habits, rest, sleep, and hygiene - to what extent the body experiences changes in physique and the fulfillment of service obligations as a chronic stressful situation. Manual hand grip strength is the most comprehensively tested physical ability test (9). Studies have shown that manual hand grip strength culminates in both sexes in the late 30 s, reaching individual highs (10-12), while longitudinal and cross-sectional studies show a decrease in both sexes from the early 50s (10-17). Measured data are higher for men at all ages than for women, and there is evidence that decline is faster in men than in women (11-13). Evidence for age-related changes in other measures of physical ability is more restricted, because this is largely limited to cross-sectional data from relatively small studies, however, this limited evidence consistently suggests that physical abilities decline gradually in later ages, furthermore, men perform better than women at all ages $(13,18-26)$. The aim of the research was to analyze the HDF BCP participants' pattern of the measurement parameters and their relationship to each other furthermore to create a measurement protocol that can be used with large number of elements, which allows the estimation of strength and fat-free mass.

\section{METHODS}

The examination was carried out in the HDF Medical Centre (Base I: 44 Robert Karoly Korut, 1134 Budapest, HUNGARY). The participants in the sample examined between 2017 and 2020 were selected from among the participants in the HDF BCP by random selection. Due to the specificity of the HDF BCP - a participant must appear on control measurements at least every 3 months during the period of 12 months, therefore, a person who is a participant throughout in the HDF BCP has been measured 5 times - one participant could be included in the sample more than once.

The sample consists of 283 persons of which $54 \%$ are women. The measured and estimated parameters of persons between 18 and 67 years of age were investigated. The age distribution of the whole sample is shown in Figure 1 while the gender-differentiated age group distribution is shown in Figures 2 and 3. Eighty-five persons were measured once, 69 persons twice, 62 persons 3 times, 48 persons 4 times, and 22 persons were measured 5 times. In case, there were

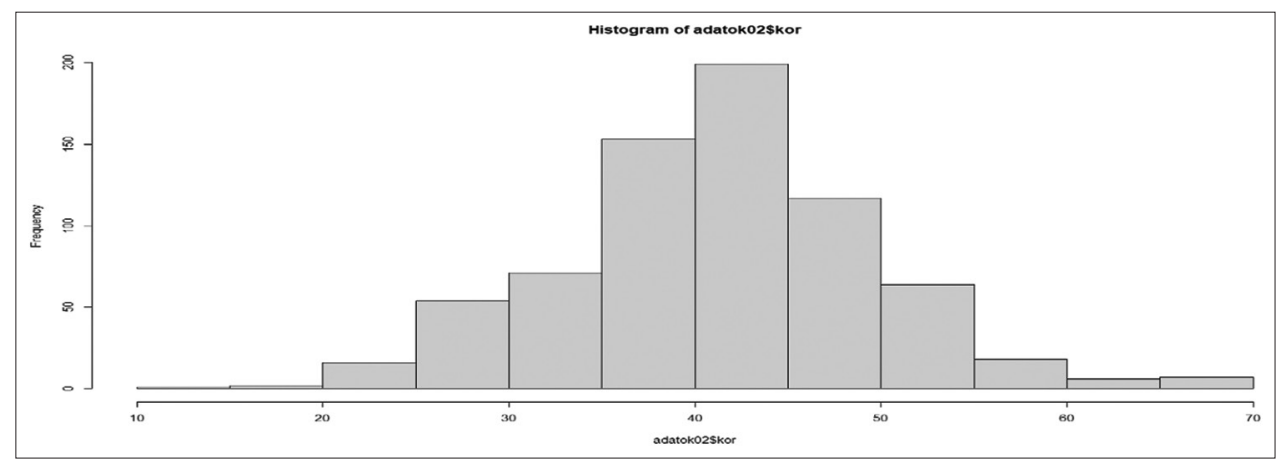

FIGURE 1. The age distribution of all persons measured under the investigation (X-axis shows the age groups of 10-70 years, Y-axis shows the size of the number of elements/person).

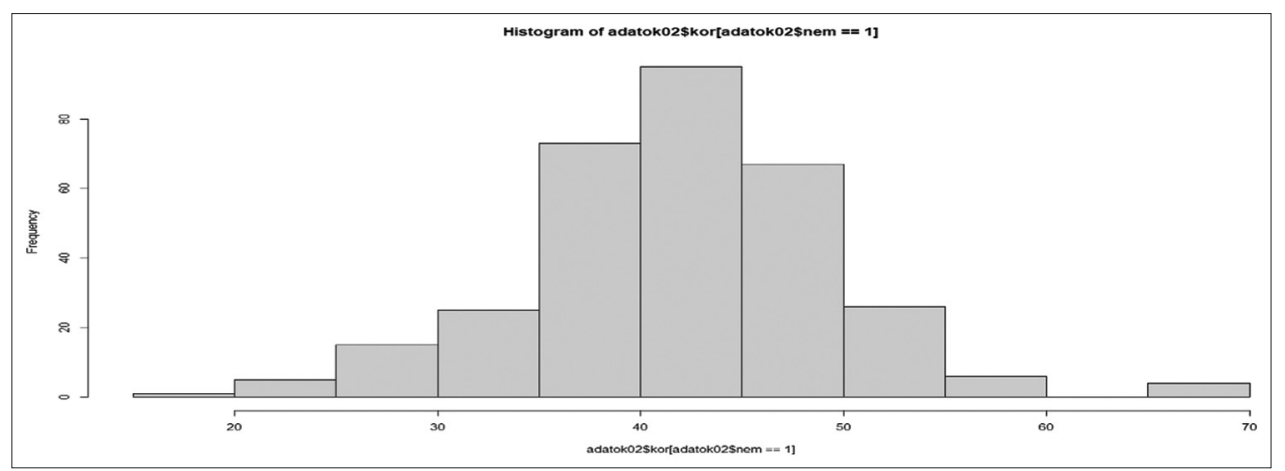

FIGURE 2. The age distribution of all men measured under the investigation (X-axis shows the age groups of 10-70 years, Y-axis shows the size of the number of elements/person). 
no significant changes in the body, fat, or fat-free mass (in case of body mass minimum $\pm 3 \mathrm{~kg}$, in case of fat mass min $\pm 2 \mathrm{~kg}$, and in case of fat-free mass $\pm 1 \mathrm{~kg}$ ), the measurement was not included in the measured sample. The data that are included in the data set were handled equally.

The device used during the examination was the Premium Body Impedance Analyzer 500, produced in Germany (SNr. 13330472/1.0) and distributed by Prémium Health Concept $\mathrm{Kft}$, which carries out body composition estimations, in the light of height and body mass, respective to age and gender with the help of the BIA software based on the bioelectric impedance $(800 / \mu \mathrm{A}, 50 \mathrm{kHz})$ established between the four electrodes placed ipsilaterally (two on the back of the hands and two on the upper feet) during the examination. The instrument measures body resistance: The resistance $(\mathrm{Rz})$ is the resistance of body water, the extracellular space and reactance $\left(X_{c}\right)$, and the intracellular space. Phase angle and $X_{c}$ are proportionate, that is, index of cell mass. The size of the phase angle decreases during the decomposition of cell mass which makes the definition of the nutritional level possible. By measuring the phase angle, the nutritional level of the body can be defined. The decreasing phase angle means increasing extracellular mass and indicates a decline in fat-free mass.

In addition, a DYNA 16 two-channel universal strength meter was used; which makes it possible to measure the grip strength of both hands at the same time (Bretz, produced in Hungary; SNr: C-0379). The result is shown in Newton as the unit of measurement.

The persons subject to the measurement were not allowed to eat $4 \mathrm{~h}$ or drink $2 \mathrm{~h}$ before measurement. Sports movements or physical activity were not allowed $12 \mathrm{~h}$ before measurement. Consuming alcohol was not allowed $24 \mathrm{~h}$ before measurement. Measurements were carried out in lying down position after the persons rested for 8-10 min.

The DYNA 16 examination was carried out in standing up position with the arms beside the body. This measurement was carried out twice within $5 \mathrm{~min}$ and the highest result was recorded.

All of the test persons gave written consent to use the data for statistical purposes. We placed great emphasis on following the ethics rules in relation to data collection and analysis (informed consent form and analysis inadequate for personal identification), the results will be communicated with the compliance of ethics rules hereinafter.

The examination was approved by the Hungarian Defence Forces, Military Medical Centre, Psychological and Health Behavior Institute (EFO/2021-3206).

A multivariate regression model was created to solve this project. Statistical calculations are performed in $\mathrm{R}$ environment with R-Studio program (Version 4.0.2, 2021.09.1+372). Quantitative data that did not follow a normal distribution are expressed as median (range) and were analyzed using the rank-sum test. Differences with $p<0.05$ were considered statistically. Quantitative data are expressed as mean (SE) standard error.

\section{RESULTS}

Descriptive statistics for the sample are shown in Table 1 for body weight, body fat and fat-free mass, and phase
TABLE 1. A descriptive statistic of the sample was a total of 708 measurements for 283 subjects

\begin{tabular}{lcccc}
\hline & $\begin{array}{c}\text { Body } \\
\text { weight }(\mathrm{kg})\end{array}$ & $\begin{array}{c}\text { Body fat } \\
(\%)\end{array}$ & $\begin{array}{c}\text { Fat-free } \\
\text { mass (\%) }\end{array}$ & $\begin{array}{c}\text { Phase angle } \\
\left(\text { Degree }^{\circ}\right)\end{array}$ \\
\hline Women & 82.2 & 41.0 & 25.8 & 5.8 \\
$(391)^{+}$ & $($SE18.5) & $($SE8.0) & $($SE3.4) & $($SE0.8) \\
Men & 103.4 & 29.2 & 33.1 & 6.6 \\
$(317)^{+}$ & $($SE19.4) & $($SE7.6) & $($SE4.3) & $($SE0.8) \\
\hline
\end{tabular}

+ : Number of measurements

angle. The results and significance levels are summarized in Table 2. Our linear regression model creation was suitable enough to measure with a high degree of accuracy the magnitude of the maximum hand grip strength, based on the data, we detected and thus the estimate of the full body strength (Table 3) as well as the estimate of the fat-free mass percentage (Table 4). In the former case, data on body weight and body fat-free mass percentage for ages and gender were required. In the latter case, data on body weight and maximum hand grip strength data were required by gender.

In this study, we did not find evidence of a decreasing trend with age in terms of hand grip strength performance for men and women, the changes did not reach the level of significance we claimed (Table 2). We found while examining the maximum hand grip strength and age that the hand grip strength decreases with the increase in age for men in the studied sample; however, these results did not show a significant difference for either men $(p=0.326)$ or women $(p=0.393)$. For women, the trend could not be confirmed. In our linear regression model, we examined among others the estimation of the maximum hand grip strength. According to this, since the error was normally distributed, the value can be estimated using the values of body weight, fat-free mass, age, and gender (Table 3). In our linear regression model, we examined the estimation of fat-free mass percentage. According to this, since the error is normally distributed in this, the value can be estimated using the values of body weight, maximum hand grip strength, and gender (Table 4).

In terms of phase angle and maximum hand grip strength, it can be said that an increase in the phase angle is accompanied by an increase in the maximum hand grip strength, consequently, the strength of the full body increases (Figure 4). Regarding body weight and hand grip strength, as body weight increases, the strength of the whole body increases according to our results (Figure 5). This tendency can also be observed if the sample is differentiated by gender (Figures 6 and 7). If the sample is differentiated according to age in each age group, the magnitude of hand grip strength also increases with the increase of body weight (Figures 8-10).

In the former case, the values of the variables such as body weight, fat-free mass, age, and gender were included in the model, while in the latter case, our linear regression model was constructed with the help of body weight, maximum hand grip strength, and the variable value of gender.

\section{DISCUSSION}

The aim of the research was to analyze the pattern of measurement parameters in the program participants and 
TABLE 2. Results of linear regression correlation of phase angle, maximum hand grip strength, body weight, and age $(n=708)$

\begin{tabular}{|c|c|c|c|c|}
\hline & Estimated value & Standard error & $\mathrm{t}$-value & $p$ \\
\hline \multicolumn{5}{|c|}{ Regarding phase angle $^{(\mathrm{C})}$ and maximum hand grip strength ${ }^{(\mathrm{N})}$} \\
\hline Independent continuous variables & 5.04 & 0.10 & 52.31 & $<0.001$ \\
\hline Maximum hand grip strength ${ }^{(4)}$ & $2.52 \times 10^{-3}$ & $2.03 \times 10^{-4}$ & 12.43 & $<0.001$ \\
\hline \multicolumn{5}{|c|}{ Regarding maximum hand grip strength ${ }^{(\mathrm{N})}$ and age (men) } \\
\hline Dependent continuous variables & 656.12 & 31.72 & 20.67 & $<0.001$ \\
\hline $\operatorname{Age}^{(5)}$ & -1.60 & 0.74 & -2.46 & 0.326 \\
\hline \multicolumn{5}{|c|}{ Regarding maximum hand grip strength ${ }^{(N)}$ and age (women) } \\
\hline Dependent continuous variables & 329.22 & 15.01 & 21.81 & $<0.001$ \\
\hline $\operatorname{Age}^{(6)}$ & 0.31 & 0.37 & 0.85 & 0.393 \\
\hline \multicolumn{5}{|c|}{ Regarding maximum hand grip strength ${ }^{(\mathrm{N})}$ and body weight ${ }^{(\mathrm{kg})}$} \\
\hline Dependent continuous variables & 138.16 & 21.13 & 6.53 & $<0.001$ \\
\hline Body weight(7) & 3.42 & 0.22 & 15.27 & $<0.001$ \\
\hline \multicolumn{5}{|c|}{ Regarding maximum hand grip strength( ${ }^{(\mathrm{N})}$ and body weight for men ${ }^{(\mathrm{kg})}$} \\
\hline Dependent continuous variables & 496.75 & 30.06 & 16.52 & $<0.001$ \\
\hline Body weight( ${ }^{(8)}$ & 0.89 & 0.29 & 3.13 & $<0.002$ \\
\hline \multicolumn{5}{|c|}{ Regarding maximum hand grip strength ${ }^{(\mathrm{N})}$ and body weight for women ${ }^{(\mathrm{kg})}$} \\
\hline Dependent continuous variables & 271.94 & 14.53 & 18.71 & $<0.001$ \\
\hline Body weight ${ }^{(9)}$ & 0.85 & 0.17 & 4.92 & $<0.001$ \\
\hline \multicolumn{5}{|c|}{ Regarding maximum hand grip strength ${ }^{(\mathrm{N})}$ and body weight ${ }^{(\mathrm{kg})}$ for ages between 10 and 35} \\
\hline Dependent continuous variables & 179.42 & 44.36 & 4.05 & $<0.001$ \\
\hline Body weight $t^{(10)}$ & 2.70 & 0.50 & 5.40 & $<0.001$ \\
\hline \multicolumn{5}{|c|}{ Regarding maximum hand grip strength ${ }^{(\mathrm{N})}$ and body weight ${ }^{(\mathrm{kg})}$ for ages between 35 and 50} \\
\hline Dependent continuous variables & 144.97 & 26.26 & 5.52 & $<0.001$ \\
\hline Body weight ${ }^{(11)}$ & 3.48 & 0.27 & 12.78 & $<0.001$ \\
\hline \multicolumn{5}{|c|}{ Regarding maximum hand grip strength ${ }^{(\mathrm{N})}$ and body weight ${ }^{(\mathrm{kg})}$ for ages $50<$} \\
\hline Dependent continuous variables & 88.83 & 62.26 & 1.43 & 0.157 \\
\hline Body weight ${ }^{(12)}$ & 3.69 & 0.68 & 5.42 & $<0.001$ \\
\hline
\end{tabular}

$\left(^{\circ}\right)$ Degree, unit of phase angle, (N) Newton, unit of hand grip strength, (kg) Kilogram, unit of body weight, (4-12) Serial number of the (regression line) diagram showing the tendency of the given relation

TABLE 3. Estimation of the maximum hand grip strength using the values of body weight, fat-free mass, age, and gender on the basis of linear regression model $(n=708)$

\begin{tabular}{lcccc}
\hline & $\begin{array}{c}\text { Estimated } \\
\text { value }\end{array}$ & $\begin{array}{c}\text { Standard } \\
\text { error }\end{array}$ & $t$-value & $p$ \\
\hline $\begin{array}{l}\text { Estimation of the maximum hand grip strength } \\
\text { Dependent }\end{array}$ & 126.14 & 73.74 & 1.71 & 0.088 \\
continuous variables & & & & \\
Body weight & 2.38 & 0.23 & 10.55 & $<0.001$ \\
Fat-free mass & 10.13 & 1.13 & 8.98 & $<0.001$ \\
Age & 0.14 & 0.35 & 0.39 & 0.700 \\
Gender & -123.56 & 13.50 & -9.15 & $<0.001$ \\
\hline $\mathrm{R}^{2}=0.74$ & & & &
\end{tabular}

TABLE 4. Estimation of the fat-free mass percent using the values of body weight, maximum hand grip strength, and gender on the basis of linear regression model $(n=708)$

\begin{tabular}{lcccc}
\hline & $\begin{array}{c}\text { Estimated } \\
\text { value }\end{array}$ & $\begin{array}{c}\text { Standard } \\
\text { error }\end{array}$ & $t$ & $p$ \\
\hline $\begin{array}{l}\text { Estimation of fat-free mass } \\
\begin{array}{l}\text { Dependent } \\
\text { continuous }\end{array}\end{array}$ & 51.25 & 1.08 & 47.32 & $<0.001$ \\
$\begin{array}{l}\text { variables } \\
\text { Body weight }\end{array}$ & -0.16 & 0.00 & -31.54 & $<0.001$ \\
$\begin{array}{l}\text { Maximum hand grip } \\
\text { strength }\end{array}$ & 0.01 & 0.00 & 9.12 & $<0.001$ \\
$\quad$ & & & & \\
\hline Gender & -8.00 & 0.34 & -23.56 & $<0.001$ \\
\hline $\mathrm{R}^{2}=0.78$ & & & &
\end{tabular}

their relationship to each other as well as to create a measurement protocol that can be used with a large number of elements, which allows the estimation of strength and fat-free mass. The indicator quality of the phase angle has already been proven in the aspect of health (8). In addition, the connection between phase angle and physical fitness has been revealed in multiple cases $(27,28)$. In each age group (children, adolescents, adults, and elderly people), a close relationship between the phase angle and fat-free mass strength, as well as aerobic capacity has been found (29). This study confirmed that the application and consideration of the phase angle can be an important indicator of a lifestyle change program, especially in the case, where the magnitude of the whole-body strength is one of the conditions for work, service, and conscription. Taking the change in the phase angle, as a quantitative index into consideration is essential in a body weight rehabilitation program in which only a slight fluctuation in the maintaining of muscle strength and cardiovascular capacity is acceptable. In the contrary case, even the combat readiness is under threat in specific armed units.

The correlation between maximum hand grip strength and whole-body strength has been supported by a number of studies and is accepted as evidence even today. In this study, we did not find evidence of a decreasing trend with age in terms of hand grip strength performance for men and women, the changes did not reach the level of significance we claimed (Table 2). The reason for this might be that the study sample includes subjects from a special population. It can be mentioned as a weakness of the present study that all subjects examined are members of armed 


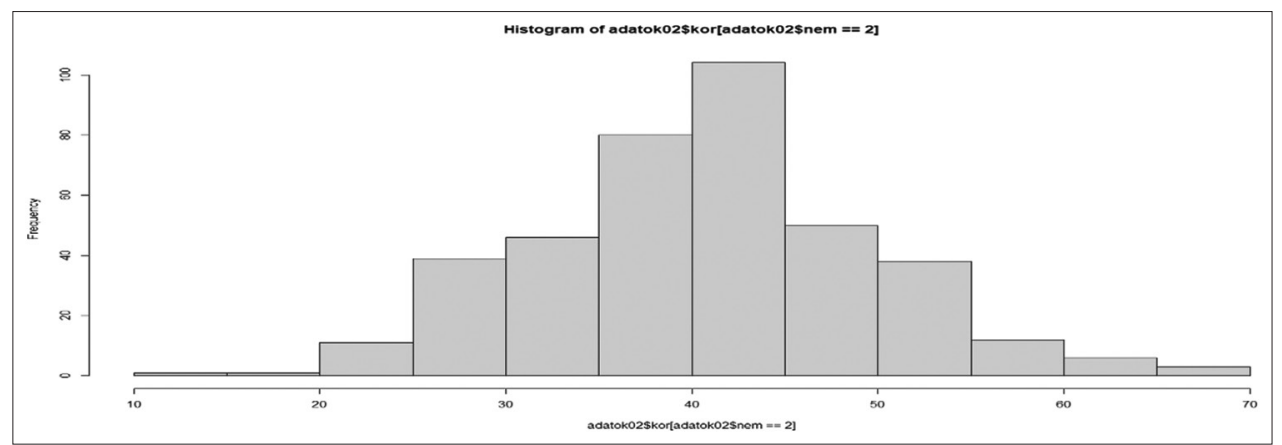

FIGURE 3. The age distribution of all women measured under the investigation (X-axis shows the age groups of 10-70 years, Y-axis shows the size of the number of elements/person).

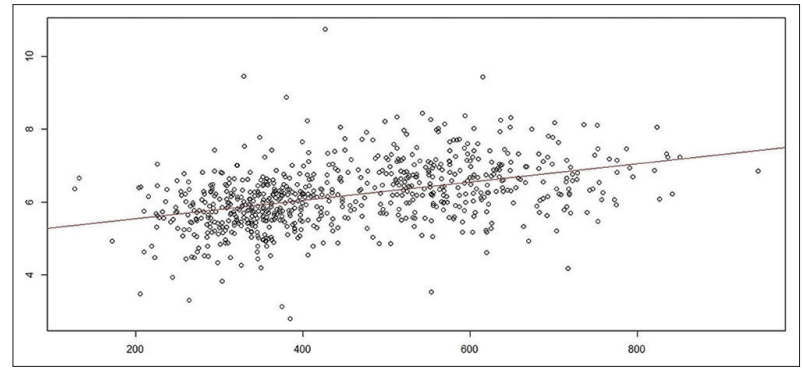

FIGURE 4. Regression line showing the tendency of the linear regression results of the phase angle (Y-axis) unit is in degrees and the maximum hand grip strength (X-axis) unit is in Newton.

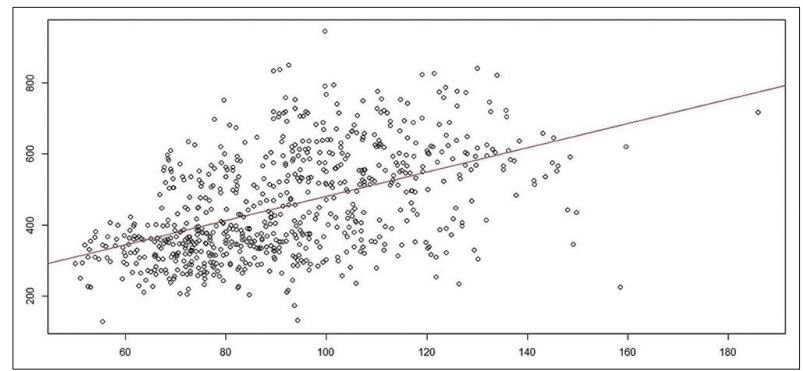

FIGURE 5. Regression line showing the tendency of the linear regression results of the maximum hand grip strength ( $Y$-axis) unit is in Newton and the body weight ( $X$-axis) unit is in kilograms.

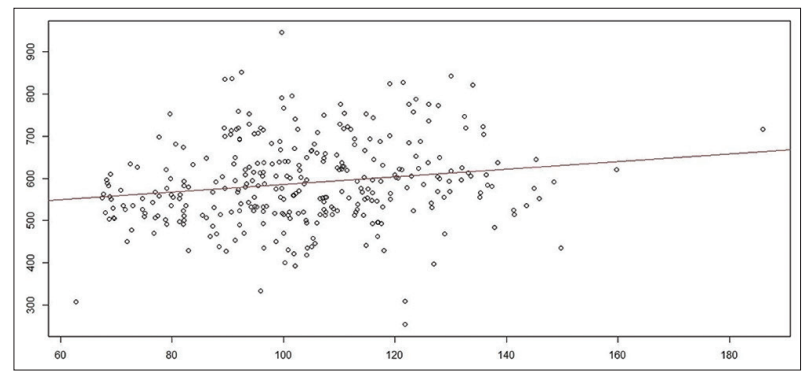

FIGURE 6. Regression line showing the tendency of the linear regression results of the maximum hand grip strength (Y-axis) unit is in Newton and the body weight (X-axis) unit is in kilograms for men.

units which means that it is not possible to generalize the results. It would be preferable to carry out these measurements in other populations and compare the results with those shown in this study.

A peculiarity of the armed services can be that everyday activities are sufficient to moderate the strength deficit increasing with age. Furthermore, the specificity of these professions is the physical fitness test, which is obligatory

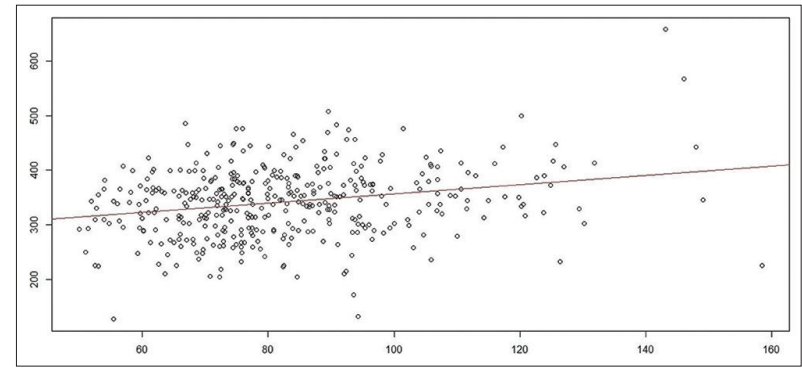

FIGURE 7. Regression line showing the tendency of the linear regression results of the maximum hand grip strength (Y-axis) unit is in Newton and the body weight (X-axis) unit is in kilograms for women.

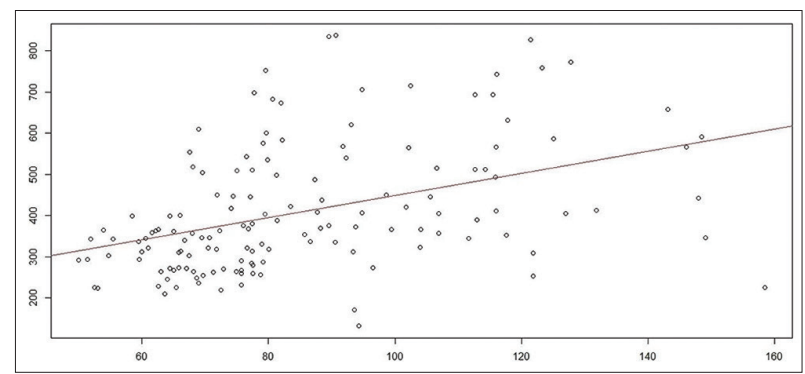

FIGURE 8. Regression line showing the tendency of the linear regression results of the maximum hand grip strength (Y-axis) unit is in Newton and the body weight unit is in kilograms of ages between 10 and 35 years (X-axis).

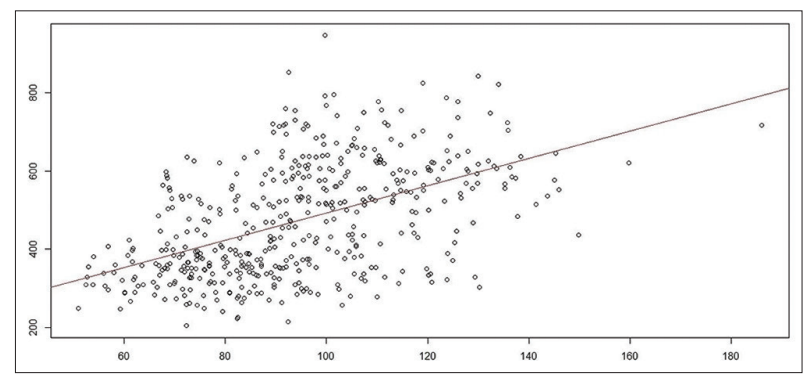

FIGURE 9. Regression line showing the tendency of the linear regression results of the maximum hand grip strength (Y-axis) unit is in Newton and the body weight unit is in kilograms of ages between 35 and 50 years (X-axis).

every year under the age of 50, is likely to be carried out, whereby some tests must be performed such as the $3200 \mathrm{~m}$ flat race for the physical fitness of the cardiovascular system and arm bending in push-ups for assessing the strength endurance of the muscles of the body and arms as well as tests from lying on the back to sit-ups performed within $2 \mathrm{~min}$ in a maximum repeated number. Although the tendency could be observed for men, there was no tendentious 


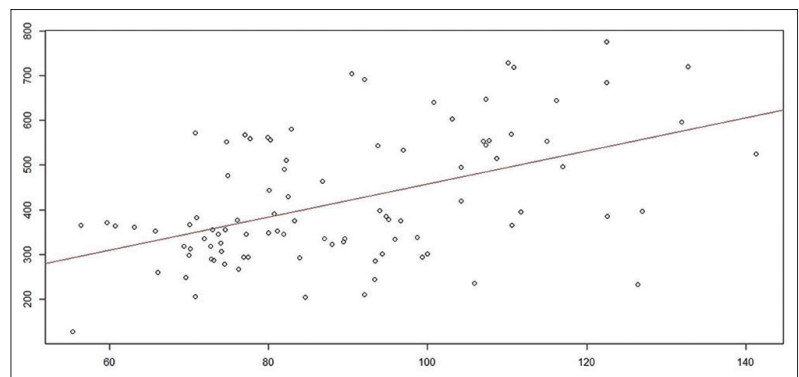

FIGURE 10. Regression line showing the tendency of the linear regression results of the maximum hand grip strength (Y-axis) unit is in Newton and the body weight of more than 50 years (X-axis) unit is in kilograms.

change for women, which needs further research to clarify. In addition, we identified that the weight gain in the study sample was accompanied by an increase in hand grip strength for both men and women. In the former case, the tendency was significantly shown while in the latter case, it was less significant. If the sample was not differentiated by gender in different age groups, weight gain was accompanied by an increase in whole-body strength in the context of younger (10-35 years), as well as middle-aged (35-50 years) and still older (older than 50) ages (Figures 8-10). These results agree with those available in the international literature $(28,29)$. Our linear regression model was able to define the fat-free mass percentage of the body as well as the magnitude of the hand grip strength using the variables we examined, thereby to infer to the strength of the full body.

Within the armed forces, during the physical fitness tests, due to able-bodiedness and military force planning, special attention is paid to processes that make it easier for populations with large number of elements to measure and estimate body composition, with special attention to body fat and fat-free mass, as fast and accurate as possible (30). The model we created is part of this effort, and after specifying it further, it can become part of the physical fitness examinations that would make the work of the staff carrying out the examinations and the staff taking part of the examinations easier.

\section{CONCLUSION}

The increasing number of the participants in the HDF BCP allows for the number of instruments in the procedure to be reduced over time by examining the correlation between variables and we can perform a large number of body composition estimates as well as estimates of parameters related to physical fitness. The created linear regression model can be the basis of a procedure, in which we will be able to estimate body fraction in significant numbers with high accuracy after measuring minimum parameters.

\section{DECLARATION OF INTEREST}

No conflicts of interest.

\section{REFERENCES}

1. Decree $10 / 2015$, of the Ministry of Defence on Health, Psychological and Physical Fitness for Military Service and the Review Procedure, 10307. Hungarian Official Gazette, No. 111; 2015. Available from: https://www.net.jogtar.hu/ jogszabaly?docid=a1500010.hm [Last accessed on $2015 \mathrm{Jul}$ 30]

2. Thibault $R$, Pichard $C$. The evaluation of body composition: A useful tool for clinical practice. Ann Nutr Metab 2012;60(1):6-16.

https://doi.org/10.1159/000334879

3. Biolo G, Cederholm T, Muscaritoli M. Muscle contractile and metabolic dysfunction is a common feature of sarcopenia of aging and chronic diseases: From sarcopenic obesity to cachexia. Clin Nutr 2014;33(5):737-48.

4. Cederholm T, Barazzoni R, Austin P, Ballmer P, Biolo G, Bischoff SC, et al. ESPEN guidelines on definitions and terminology of clinical nutrition. Clin Nutr 2017;36(1):49-64

https://doi.org/10.1016/j.clnu.2016.09.004

5. Forbes A, Escher J, Hebuterne X, Klek S, Krznaric Z, Schneider S, et al. ESPEN guideline: Clinical nutrition in inflammatory bowel disease. Clin Nutr 2017;36(2):321-47.

https://doi.org/10.1016/j.clnu.2016.12.027

6. Cederholm T, Bosaeus I, Barazzoni R, Bauer J, van Gossum A, Klek S, et al. Diagnostic criteria for malnutrition-an ESPEN consensus statement. Clin Nutr 2015;34(3):335-40. https://doi.org/10.1016/j.clnu.2015.03.001

7. Gupta D, Lammersfeld CA, Burrows JL, Dahlk SL, Vashi PG, Grutsch JF, et al. Bioelectrical impedance phase angle in clinical practice: Implications for prognosis in advanced colorectal cancer. Am J Clin Nutr 2004;80(6):1634-38. https://doi.org/10.1093/ajcn/80.6.1634

8. Barbosa-Silva MC, Barros AJ. Bioelectrical impedance analysis in clinical practice: A new perspective on its use beyond body composition equations. Curr Opin Clin Nutr Metab Care 2005;8(3):311-7.

https://doi.org/10.1097/01.mco.0000165011.69943.39

9. Cooper R, Hardy R, Sayer AA, Kuh D. A life course approach to physical capability. In: Kuh D, Cooper R, Hardy R, Richards M, Ben-Shlomo Y, editors. A Life Course Approach to Healthy Ageing. Oxford, US: Oxford University Press; 2014. p. 16-31.

10. Kallman DA, Plato CC, Tobin JD. The role of muscle loss in the age-related decline of grip strength: Cross-sectional and longitudinal perspectives. J Gerontol 1990;45(3):M82-8

https://doi.org/10.1093/geronj/45.3.m82

11. Lindle RS, Metter EJ, Lynch NA, Fleg JL, Fozard JL, Tobin J, et al. Age and gender comparisons of muscle strength in 654 women and men aged 20-93 yr. J Appl Physiol 1997;83(5):1581-87.

https://doi.org/10.1152/jappl.1997.83.5.1581

12. Metter EJ, Conwit R, Tobin J, Fozard JL. Age-associated loss of power and strength in the upper extremities in women and men. J Gerontol A Biol Sci Med Sci 1997;52(5):B267-76

https://doi.org/10.1093/gerona/52a.5.b267

13. Cooper R, Hardy R, Sayer AA, Ben-Shlomo Y, Birnie K, Cooper C, et al. Age and gender differences in physical capability levels from mid-life onwards: The harmonisation and metaanalysis of data from eight UK cohort studies. PLoS One 2011;6(11):e27899.

https://doi.org/10.1371/journal.pone.0027899

14. Rantanen T, Masaki K, Foley D, Izmirlian G, White L, Guralnik JM. Grip strength changes over 27 year in Japanese-American men. J Appl Physiol 1998;85(6):2047-53.

https://doi.org/10.1152/jappl.1998.85.6.2047

15. Rantanen T, Era P, Heikkinen E. Physical activity and the changes in maximal isometric strength in men and women from the age of 75 to 80 years. J Am Geriatr Soc 1997;45(12):1439-45.

https://doi.org/10.1111/j.1532-5415.1997.tb03193.x

16. Bassey EJ. Longitudinal changes in selected physical capabilities: Muscle strength, flexibility and body size. Age Ageing 1998; 27 Suppl 3:12-6.

https://doi.org/10.1093/ageing/27.suppl_3.1

17. Forrest KYZ, Zmuda JM, Cauley JA. Patterns and correlates of muscle strength loss in older women. Gerontology 2007;53(3):140-7.

https://doi.org/10.1159/000097979

18. Bohannon RW. Reference values for the timed up and go test: A descriptive meta-analysis. J Geriatr Phys Ther 2006;29(2):64-8. https://doi.org/10.1519/00139143-200608000-00004

19. Bohannon RW. Single limb stance times a descriptive meta-analysis of data from individuals at least 60 years of age. Top Geriatr Rehabil 2006;22(1):70-7. https://doi.org/10.1097/00013614-200601000-00010

20. Michikawa T, Nishiwaki Y, Takebayashi T, Toyama Y. One-leg standing test for elderlypopulations. J Orthop Sci 2009;14(5):675-85. https://doi.org/10.1007/s00776-009-1371-6

21. Wang YC, Magasi SR, Bohannon RW, Reuben DB, McCreath HE, Bubela DJ, et al. Assessing dexterity function: A comparison of two alternatives for the NIH toolbox. J Hand Ther 2011;24(4):313-20. https://doi.org/10.1016/j.jht.2011.05.001 
22. Samson MM, Meeuwsen IB, Crowe A, Dessens JA, Duursma SA, Verhaar HJ. Relationships between physical performance measures, age, height and body weight in healthy adults. Age Ageing 2000;29(3):235-42 https://doi.org/10.1093/ageing/29.3.235

23. Bohannon RW. Comfortable and maximum walking speed of adults aged 20-79 years: Reference values and determinants. Age Ageing 1997;26(1):15-9.

https://doi.org/10.1093/ageing/26.1.15

24. Tsubaki A, Kubo M, Kobayashi R, Jigami H, Takahashi HE. Age-related changes in physical function in community-dwelling people aged 50-79 years. J Phys Ther Sci 2010;22:23-7. https://doi.org/10.1589/jpts.22.23

25. Himann JE, Cunningham DA, Rechnitzer PA, Paterson DH. Age-related changes in speed of walking. Med Sci Sports Exerc 1988;20(2):161-6. https://doi.org/10.1249/00005768-198820020-00010

26. Kimura M, Mizuta C, Yamada Y, Okayama Y, Nakamura E. Constructing an index of physical fitness age for Japanese elderly based on 7-year longitudinal data: Sex differences in estimated physical fitness age. Age (Dordr) 2012;34(1):203-14 https://doi.org/10.1007/s11357-011-9225-5

27. Langer RD, de Fatima Guimarães R, Gonçalves EM, Guerra G Jr., de Moraes AM. Phase angle is determined by body composition and cardiorespiratory fitness in adolescents. Int J Sports Med 2020;41(9):610-5.

https://doi.org/10.1055/a-1152-4865

28. Gonzalez MC, Barbosa-Silva TG, Bielemann RM, Gallagher D, Heymsfield SB. Phase angle and its determinants in healthy subjects: Influence of body composition. Am J Clin Nutr 2016;103(3):712-6.

https://doi.org/10.3945/ajcn.115.116772

29. Martins PC, de Lima TR, Silva AM, Silva DA. Association of phase angle with muscle strength and aerobic fitness in different populations: A systematic review. Nutrition 2022;93:111489.

https://doi.org/10.1016/j.nut.2021.111489.

30. AR 600-9: The Army Body Composition Program; 2013. Available from: http:// www.wood.army.mil/sap-per/document frames/ar600_9.pdf [Last accessed on 2013 Jun 28].

\section{RELATED ARTICLES PUBLISHED IN JHSCI}

1. Pluncevikj Gligoroska J, Manchevska S, Efremova L, Todorovska L, Nikolic S. Body composition and maximal oxygen consumption in adult soccer players in the Republic of Macedonia. JHSCI. 2015;5(3):85-92. 